\title{
A NOTE OF CORRECTION
}

In my review of Watt's The Foundations of Music (Psychol. BuLl., 1921, I8, 497-500) I have stated that "in applying his theory of fusion and interval to musical usage, Watt is forced to emphasize harmonic structure at the expense of simple melody." Through an inexcusable inadvertence I was led to support this view with a quotation which in its proper context was intended by the author to convey a contrary meaning. "Without harmony, which is the 'perpendicular' complement to the 'horizontal' functions of melody, we have a music which hardly deserves the name of art. It is merely primitive play, as it were" (p. 16I). This extreme conclusion which appears to deny any system to the musical usage of the non-harmonic scales employed in the Orient is indicative of the influence a theory may exert over the facts it attempts to organize (p. 499). What the author actually states is that harmony has usually been put down as the one and only basis of true music, from which would follow that non-harmonic music "hardly deserves the name of art," but he adds that "an almost contrary thesis may be vigorously maintained."

While I greatly regret the carelessness with which my quotation was selected, and seek now to correct the impression I gave that Watt regards melody as secondary to harmony in musical evolution, I am unable to amend my conclusion that "many things like the pattern of pure melody seem to be neglected because they do not readily fall within the conception dominating the author's mind." It is against his conception of fusion and his derivation of the musical intervals therefrom that my argument was mainly directed and I am still unconvinced that Watt's foundations are adequate to explain melody.

R. M. Ogden

Cornell Untverstty 